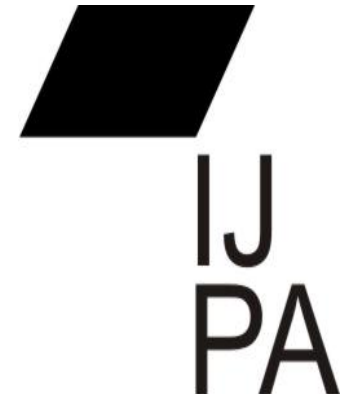

ISSN $2460-0369$

\section{PENGARUH KOMUNIKASI, SUMBER DAYA, DISPOSISI DAN STRUKTUR BIROKRASI TERHADAP EFEKTIFITAS IMPLEMENTASI PROGRAM BANTUAN OPERASIONAL SEKOLAH PADA SATUAN PENDIDIKAN SEKOLAH DASAR NEGERI DI KECAMATAN TAMBAK}

\author{
Mening Subekti, Muslih Faozanudin, Ali Rokhman
}

\author{
Program Pasca Sarjana Ilmu Administrasi \\ Universitas Jenderal Soedirman \\ ning.subekti@yahoo.com
}

\begin{abstract}
Implementation is one of public policy process, that is crucial because it must be well prepared for the effective purpose. In Indonesia, $B O S$ is one of public policy. Based on the data, shows an indication of implementation BOS hasn't been optimal in Tambak sub-district. The conception of the authors apply some theories and concepts related to the study variables from several experts including George C Edward III, Merilee S. Grindle, Daniel A. Mazmanian and Paul A. Sabatier, Van Meter and Van Horn, to explain the relationship between independent variables with dependent variable. The located research in Tambak subdistrict with sample are26 elementary schools. The research method used is quantitative analysis, the data obtained by questionnaire answers were analyzed with Kendall's Tau, Konkordansi Kendall's $W$ and ordinal regression. Based on the findings of this study, the variable of bureaucratic structure need to be increased. Therefore, research is needed to assess the effect of bureaucratic structure variables to effectiveness of implementation.
\end{abstract}

Keywords : Effectiveness, Implementation, and BOS.

\begin{abstract}
Abstrak: Implementasi merupakan proses dari kebijakan publik yang bersifat krusial karena harus dipersiapkan denganbbaik agar tjuan berjalan efektif. Salah satu program kebijakan pemerintah yaitu program BOS. Berdasarkan data di lapangan, menunjukkan indikasi belum optimalnya implementasi BOS di Kecamatan Tambak. Secara konsepsi, teori yang berkaitan dengan variabelvariabel penelitian diantaranya George C. Edward III, Merilee S. Grindle, Daniel A. Mazmanian dan Paul A. Sabatier, serta Van Meter dan Van Horn guna menjelaskan hubungan a $\mathrm{n} t$ a $\mathrm{r}$ variabel. Lokasi penelitian ini dilaksanakan di Kecamatan Tambak dengan 26 sampel SD Negeri. Metode penelitian yang digunakan bersifat analisis kuantitatif, data yang diperoleh berdasarkan jawaban kuesioner dianalisis dengan kendall's Tau, konkordansi kendall's W serta regresi ordinal untuk mengetahui pengaruh antara variabel independen dengan variabel dependen. Berdasarkan hasil temuan penelitian ini, efektivitas implementasi BOS di Kecamatan Tambak perlu ditingkatkan. Pada variabel struktur birokrasi menunjukkan hasil yang masih berpengaruh sedang terhadap efektivitas implementasi BOS di kecamatan Tambak. Oleh karena itu, perlu penelitian lebih lanjut guna mengkaji variabel struktur birokrasi terhadap efektivitas implementasi.
\end{abstract}

Kata kunci : Efektivitas, Implementasi, Dan BOS. 


\section{PENDAHULUAN}

Implementasi kebijakan publik merupakan salah satu tahapan dari proses kebijakan publik (public police process) sekaligus studi yang sangat crusial. Menurut Widodo (2010 : 85) implementasi kebijakan publik bersifat crusial karena bagaimanapun baiknya suatu kebijakan, jika tidak dipersiapkan dan direncanakan secara baik dalam implementasinya, maka tujuan kebijakan tidak akan bisa diwujudkan. Program BOS mendapatkan alokasi sebesar $20 \%$ dari APBN. Secara khusus program BOS bertujuan untuk: a) Menggratiskan seluruh siswa miskin di tingkat pendidikan dasar dari beban biaya; b) operasional sekolah, baik di sekolah negeri maupun sekolah swasta; c) Menggratiskan seluruh siswa SD negeri dan SMP negeri terhadap biaya operasional sekolah, kecuali pada rintisan sekolah bertaraf internasional (RSBI) dan sekolah bertaraf internasional (SBI); dan d) Meringankan beban biaya (Panduan BOS, 015).

Mekanisme pelaksanaan harus dilakukan secara efektif sesuai dengan Buku Panduan BOS agar tujuan dapat tercapai. Namun dalam kondisi nyata banyak terkendala yang disebabkan karena banyaknya aturan penggunaan dan larangan penggunaan dana BOS membuat pihak sekolah sulit membelanjakan dana BOS untuk peningkatan mutu pendidikan dasar, termasuk ketentuan ketentuan pembelian buku yang telah ditentukan di dalam juknis BOS. Dengan memperhatikan penjelasan permasalahan tersebut, peneliti tertarik untuk meneliti sejauh mana pengaruh komunikasi, sumber daya, disposisi dan struktur birokrasi terhadap efektifitas implementasi program BOS di kecamatan Tambak.

\section{Rumusan Masalah}

"Bagaimana pengaruh komunikasi, sumber daya, disposisi, dan struktur birokrasi terhadap efektivitas implementasi bantuan operasional sekolah (BOS) pada Sekolah Dasar Negeri di Kecamatan Tambak".

\section{Tujuan}

Untuk menganalisis pengaruh komunikasi, sumber daya, disposisi, dan struktur birokrasi terhadap efektivitas implementasi bantuan operasional sekolah (BOS) pada Sekolah Dasar Negeri di Kecamatan Tambak. 


\section{Manfaat}

Diharapkan penelitian yang akan dilakukan dapat menjadi tambahan referensi atau acuan bagi mahasiswa maupun pihak lain dan sebagai bahan penelitian selanjutnya untuk mengembangkan dan menyempurnakan penelitian ini.

\section{LANDASAN TEORI}

\section{Implementasi Kebijakan}

\section{Teori George C. Edward}

Edward III (dalam Subarsono, 2011: 90-92) berpandangan bahwa implementasi kebijakan dipengaruhi oleh empat variabel antara lain komunikasi, yaitu keberhasilan implementasi kebijakan mensyaratkan agar implementor mengetahui apa yang harus dilakukan. Sumber daya, meskipun isi kebijakan telah dikomunikasikan secara jelas dan konsisten, tetapi apabila implementor kekurangan sumberdaya untuk melaksanakan, maka efektivitas implementasi menjadi terkendala. Disposisi, watak dan karakteristik yang dimiliki oleh implementor, seperti komitmen, kejujuran, sifat demokratis. Apabila implementor memiliki disposisi yang baik, maka tujuan kebijakan dapat tercapai. Struktur birokrasi, bertugas mengimplementasikan kebijakan disposisi terdiri dari aspek pada struktur organisasi yakni Standard Operating Procedure (SOP) dan fragmentasi.

2. TeoriMerilee S. Grindle

Keberhasilan implementasi menurut Merilee S. Grindle (dalam Subarsono, 2011: 93) dipengaruhi oleh dua variabel besar, yakni isi kebijakan (content of policy) dan lingkungan implementasi (context of implementation). Variabel tersebut mencakup: sejauhmana kepentingankelompok sasaran atau target group termuat dalam isi kebijakan, jenis manfaat yang diterima oleh target group, sejauhmana perubahan yang diinginkan dari sebuah kebijakan

3. Teori Daniel A. Mazmanian dan Paul A. Sabatier

Menurut Mazmanian dan Sabatier (dalam Subarsono, 2011: 94) ada tiga kelompok variabel yang mempengaruhi keberhasilan implementasi, yakni 
karakteristik dari masalah (tractability of the problems), karakteristik kebijakan/undang-undang (ability of statute to structure implementation) dan variabel lingkungan (nonstatutory variables affecting implementation).

\section{Teori Van Meter dan Van Horn}

Menurut Van Meter dan Van Horn (Subarsono, 2005: 99) terdapat lima variabel yang mempengaruhi implementasi kebijakan yaitu : “(1) standar dan sasaran kebijakan; (2) sumberdaya; (3) komunikasi antarorganisasi dan penguatan aktivitas; (4) karakteristik agen pelaksana; dan (5) kondisi sosial, ekonomi dan politik".

Penelitian ini menggunakan model implementasi dari teori George C. Edward III. Edwards III menilai implementasi kebijakan sebagai suatu proses yang dinamis, dimana terdapat banyak faktor yang saling berinteraksi dan mempengaruhi implementasi kebijakan. Menurut Edwards (dalam Widodo, 2011: 96-110), ada 4 (empat) faktor yang mempengaruhi keberhasilan maupun kegagalan dalam implementasi kebijakan. Keempat faktor itu adalah: komunikasi (communication), sumber daya manusia (resource), sikap (disposision), dan struktur birokrasi (beureucratic structure). Berikut merupakan bagan faktor-faktor pengaruh implementasi kebijakan publik model George Edwards III :

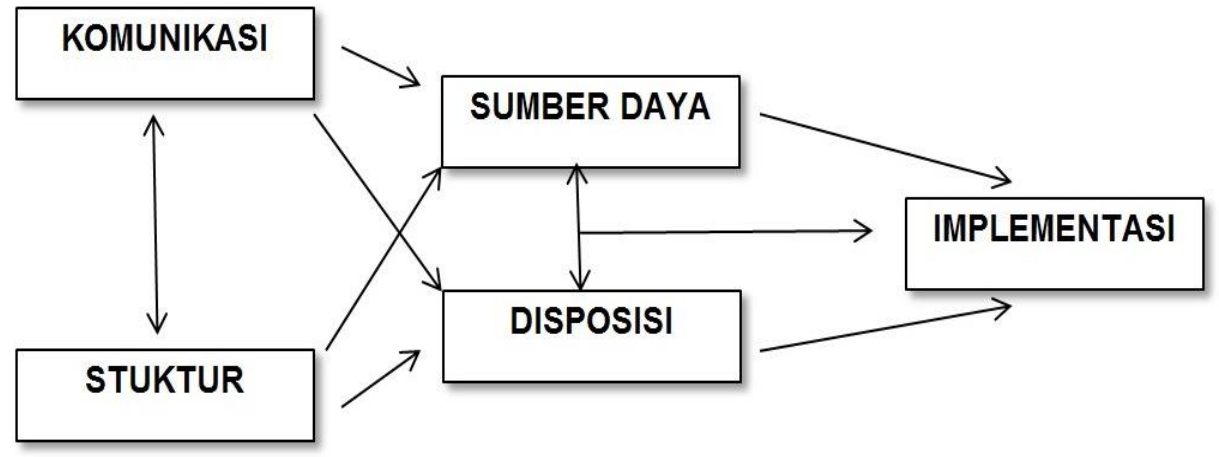

Gambar 1. Model Implementasi George Edwards III Sumber: Edwards III dikutip dari Subarsono (2011: 91) 


\section{Efektifitas Implementasi}

Efektivitas merupakan unsur pokok untuk mencapai tujuan atau sasaran yang telah ditentukan di dalam setiap organisasi, kegiatan ataupun program. Disebut efektif apabila tercapai tujuan ataupun sasaran seperti yang telah ditentukan. Menurut pendapat Mahmudi (2005 : 92) "Efektivitas merupakan hubungan antara output dengan tujuan, semakin besar ontribusi (sumbangan) output terhadap pencapaian tujuan, maka semakin efektif organisasi, program atau kegiatan”. Efektivitas berfokus pada outcome (hasil), program, atau kegiatan yang dinilai efektif apabila output yang dihasilkan dapat memenuhi tujuan yang diharapkan atau dikatakan spending wisely.

Pengukuran out comes merupakan pengukuran kinerja yang paling penting, nama lain dari pengukuran outcomes adalah pengukuran efetivitas. Pengukuran efektivitas adalah penilaian terhadap kaitan antara realitas produk yang dihasilkan suatu kegiatan atau program dengan target outcomes yang diharapkan. Pendekatan pengukuran outcomes dapat dilakukan dengan berbagai cara, tidak hanya melalui penilaian numeric saja tetapi bisa dalam bentuk pembuktian melalui observasi, catatan data sekunder, rekaman video/foto, atau hasil interviu dengan penerima manfaat (Lukito, 2014 : 64).

Menurut Steers (dalam Sagala, 2006), mengungkapkan keefektifan seringkali diartikan kuantitas atau kualitas keluaran (output) barang atau jasa. Namun perlu ditambahkan bahwa bagi organisasi seperti sekolah, keefektifan adalah kemampuan mengelola sumber daya secara optimal (pemanfaatan), yaitu menunjukkan sejauhmana organisasi melaksanakan seluruh tugas pokoknya secara baik dan benar untuk mencapai tujuan.

\section{METODE PENELITIAN}

Penelitian ini menggunakan metode kuantitatif dengan metode rancangan penelitian survai eksplanatori (Sugiyono, 2012:21). Penelitian dengan pendekatan kuantitatif menekankan analisisnya pada data-data numerikal (angka) yang diolah dengan metode statistika. Pada dasarnya, pendekatan kuantitatif dilakukan pada penelitian inferensial (dalam rangka pengujian hipotesis) dan menyandarkan kesimpulan hasilnya pada suatu probabilitas. 


\section{HASIL PENELITIAN DAN PEMBAHASAN}

\section{Pengaruh Komunikasi terhadap Efektivitas Implementasi BOS di Kecamatan Tambak}

Komunikasi mempunyai peranan yang sangat penting dalam penyampaian suatu kebijakan, oleh karena itu kebijakan yang akan disampaikan harus di pahami dengan baik oleh pelaksananya. Dengan demikian kebijakan tersebut dapat dikomunikasikan dan disebarkan dengan jelas, akurat dan konsisten serta tidak menimbulkan kontradiksi. Hasil penelitian menujukkan bahwa dimensi komunikasi mempunyai pengaruh positif terhadap efektivitas implementasi BOS di Kecamatan Tambak. Dilihat dari uji menggunakan kendall's tau b yang dihasilkan yakni $0,849 * *$ hal ini menunjukkan ada pengaruh yang sangat kuat dengan arah yang positif artinya semakin tinggi intensitas komunikasi (X1) semakin tinggi pula efektivitas implementasi BOS di Kecamatan Tambak (Y) dan sebaliknya semakin rendah intensitas komunikasi semakin rendah pula efektivitas implementasi BOS di kecamatan Tambak seperti yang dihasilkan dari uji regresi ordinal dengan nilai estimate semakin buruk komunikasi di lokasi penelitian maka akan semakin menurunkan efektivitas implementasi BOS.

Fungsi komunikasi dari implementasi kebijakan pemerintah meliputi tiga aspek yaitu transmisi, kejelasan, dan konsistensi. Hal ini sesuai dengan pendapat Edward III (dalam Subarsono 2011 : 90) dimana dimensi komunikasi meliputi transformasi (transmission), kejelasan (clarity), dan konsistensi (consistency).

Berdasarkan observasi dan studi dokumentasi bahwa Komunikasi dalam implementasi BOS di Kecamatan Tambak dilakukan dalam sosialisasi antara dinas pendidikan kepada sekolah, maupun antara sekolah dengan masyarakat. penyampaian pesan yang dilakukan pemerintah adalah melalui sosialisasi secara langsung maupun tidak langsung, secara langsung biasanya pada saat kegiatan sosialisasi atau workshop BOS yang diadakan di balai pertemuan atau kantor dinas. Antara kepala sekolah dengan guru, komite, dan bendahara bersinergi dalam pengelolaan BOS. pelaporan atas penggunaan dana BOS disampaikan dengan baik kepada komite dan wali murid pada kegiatan rapat berkala. Hal tersebut dilakukan agar masyarakat mengetahui penggunaan dana BOS dan 
kondisi keuangan sekolah. Dari segi komunikasi hambatan yang terjadi adalah pesan yang disampaikan dalam iklan sekolah gratis, menimbulkan pro dan kontra ditengah masyarakat walaupun iklan sekolah gratis sudah diklarifikasi tetapi tetap saja tingkat pemahaman dan kesadaran masyarakat akan sekolah gratis masih rendah

Sebagaimana penelitian dari Ninik Purwaning S (2010), Desy Natalia Krisdayanti (2014), Abdullah Wahid (2014), dan Yuyun Sefri Setyaningrum (2016) menjelaskan bahwa kebersihasilan implementasi kebijakan masyaratkan agar implementor mengetahui apa yang harus dilakukan. Agustino (2006:157) menyatakan bahwa "komunikasi merupakan salah-satu variabel penting yang mempengaruhi implementasi kebijakan publik, komunikasi sangat menentukan keberhasilan pencapaian tujuan dari implementasi kebijakan publik. Dengan demikian, untuk lebih meningkatkan efektivitas implementasi BOS di Kecamatan Tambak hendaknya aturan mengenai kebijakan pemerintah dalam implementasi BOS di Kecamatan Tambak dapat dikomuniasikan dan disosialisasikan dengan baik sehingga setiap aturan dan prosedur pada pelaksanaan dapat dipahami dan diikuti oleh seluruh lembaga sekolah dan diterima oleh masyarakat. Seperti yang dikatakan oleh Lasswell (dalam David, 2003 : 52) yang mengungkapkan bahwa komunikasi pada dasarnya merupakan suatu proses yang menjelaskan siapa? mengatakan apa? dengan saluran apa? kepada siapa? dengan akibat atau hasil apa? (who? says what? in which channel? to whom? with what effect?, sehingga implementasi berjalan dengan efektif.

\section{Pengaruh Sumber Daya terhadap Efektivitas Implementasi BOS di Kecamatan Tambak}

Implementasi suatu kebijakan cenderung menjadi tidak efektif, meskipun perintah-perintah implementasi diteruskan (ditransmisikan) secara cermat, jelas dan konsisten, apabila memiliki kekurangan sumber-sumber yang diperlukan oleh pelaksana untuk menjalankan kebijakan. Hasil penelitian menujukkan bahwa dimensi sumber daya berpengaruh terhadap efektivitas implementasi BOS di Kecamatan Tambak. dengan nilai koefisien Kendall's Tau b yang dihasilkan yakni $0,818^{* *}$ hal ini menunjukkan ada pengaruh yang sangat kuat dengan arah 
yang positif artinya semakin tinggi sumber daya (X2) semakin tinggi pula efektifitas implementasi BOS di Kecamatan Tambak (Y) dan sebaliknya semakin rendah sumber daya semakin rendah pula efektivitas implementasi BOS di kecamatan Tambak seperti yang dihasilkan dari uji regresi ordinal dengan estimate semakin buruk sumber daya di lokasi penelitian maka akan semakin menurunkan efektivitas implementasi BOS.

Dari hasil observasi dan dokumentasi, dukungan sumber daya dalam efektivitas implementasi BOS di Kecamatan Tambak. antara lain adanya ketersediaan pegawai/staff, ketersediaan dana, kewenangan yang jelas, serta adanya ketersediaan fasilitas sarana dan prasarana. Dari segi SDM baik secara kuantitas maupun kualitas sudah memadai terlihat dari tercapainya pelaporan pengelolaan dana BOS baik berkala maupn tahunan. Meskipun belum ada staff khusus yang berkompeten dari bidang akuntasi maupun administasi, namun pelaporan dapat berjalan lancar dan pencairan BOS tidak terhambat. SDM begitu berpengaruh pada keberhasilan suatu implementasi kebijakan, sebab tanpa SDM yang handal implementasi kebijakan hanya akan menemui kegagalan. Antara kepala sekolah, komite, guru dan bendahara membuat perencanaan kegiatan dan agenda pembelajaran yang disesuaikan dengan kemampuan dana yang dilimiliki sekolah. Sehingga rencana yang telah ditetapkan dapat berjalan dengan efektif baik dalam kegiatan kurikuler maupun non kurikuler serta pengadaan sarana dan prasarana penunjang yang dibutuhkan selama pembelajaran. Permasalahan umum yang muncul selain belum tersedia staff khusus, permaaslahan lain yakni terkait dengan keterbatasan jumlah staf dalam program kebijakan pemerintah adalah munculnya program atau tugas baru namun tidak diikuti dengan penambahan staf baru sehingga seorang staff harus menyelesaikan berbagai macam tugas.

Sebagaimana penelitian dari Ninik Purwaning S (2010), Desy Natalia Krisdayanti (2014), Abdullah Wahid (2014), dan Yuyun Sefri Setyaningrum (2016) menjelaskan bahwa titik sentral dari Jalan tidaknya implementasi kebijakan terletak pada sumber daya. Meskipun isi kebijakan sudah dikumonikasikan secara jelas dan konsisten, tetapi apabila impelementor 
kekurangan sumber daya untuk melaksanakan, implementasi tidak akan berjalan efektif. Disamping itu, sesuai dengan pendapat Edward III (dalam Subarsono 2011 : 90) bahwa sumber-sumber penting dalam mendukung pelaksanaan implementasi kebijakan pemerintah antara lain staf atau SDM, anggaran, fasilitas dan wewenang. Hal tersebut menjadi bukti nyata, bahwa sumber daya manusia, anggaran maupun sarana dan prasarana dapat mempengaruhi efektivitas implementasi kebijakan.

\section{Pengaruh Disposisi terhadap Efektivitas Implementasi BOS di Kecamatan Tambak}

Disposisi atau sikap pelaksana akan menimbulkan hambatan-hambatan yang nyata terhadap implementasi kebijakan bila personel yang ada tidak melaksanakan kebijakan yang diinginkan. Karena itu, pelaksana kebijakan haruslah orang-orang yang memiliki dedikasi pada kebijakan yang telah ditetapkan.

Hasil penelitian menujukkan bahwa dimensi berpengaruh terhadap efektivitas implementasi BOS di Kecamatan Tambak.dengan nilai koefisien kendall's tau b yang dihasilkan yakni $0,821^{* *}$ hal ini menunjukkan ada pengaruh yang sangat kuat dengan arah yang positif artinya semakin tinggi disposisi (X3) semakin tinggi pula efektifitas implementasi BOS di Kecamatan Tambak (Y) dan sebaliknya semakin rendah disposisi semakin rendah pula efektivitas implementasi BOS di kecamatan Tambak seperti yang dihasilkan dari uji regresi ordinal dengan estimate semakin buruk disposisi di lokasi penelitian maka akan semakin menurunkan efektivitas implementasi BOS.

Dari hasil observasi, Implementasi kebijakan BOS di kecamatan Tambak didukung oleh kecenderungan yang baik antar pelaksana terhadap implementasi BOS. Secara umum kepala sekolah mau dan mampu menerapkan program BOS sesuai dengan aturan yang ada. Selain adanya dukungan dari kepala sekolah, guru dan komite, orang tua siswa juga turut mendukung adanya kebijakan BOS. Tidak hanya keuntungan yang diperoleh oleh wali murid karena adanya keringanan biaya sekolah. Namun, wali murid juga tetap menyetujui tentang biaya yang ada di luar kebijakan BOS. Para pelaksana bekerja sama dan saling mendukung dalam 
pelaporan dan pengelolaan BOS. Adanya insentif yang diberikan oleh sekolah meskipun tidak banyak namun para pelaksana tetap semangat mengerjakan pelaporan BOS meskipun dikejar oleh batas waktu pengumpulan laporan. Pada akhirnya semua sekolah dapat melaporkan keuangan BOS sesuai dengan waktu yang ditetapkan.Tuntutan kemampuan dalam melaksanakan kebijakan didukung dengan adanya kemauan untuk menerapkan kebijakan tersebut.

Hal ini sejalan dengan hasil penelitian dari Ninik Purwaning S (2010), Desy Natalia Krisdayanti (2014), Abdullah Wahid (2014), dan Yuyun Sefri Setyaningrum (2016) yang menjelaskan bahwa disposisi adalah watak dan karakteristik yang dimiliki oleh implementor, seperti komitmen, kejujuran, sifat demokratis. Apabila implementor memiliki disposisi yang baik, maka kebijakan akan berjalan dengan baik seperti yang diinginkan oleh pembuat kebijakan. Ketika implementor memiliki sikap atau perpektif yang berbeda dengan pembuat kebijakan, maka proses implementasi kebijakan juga menjadi tidak efektif.

\section{Pengaruh Struktur Birokrasi terhadap Efektivitas Implementasi BOS di Kecamatan Tambak}

Struktur birokrasi merupakan salah satu faktor yang berpengaruh terhadap efektivitas implementasi. Ketika strukur birokrasi tidak kondusif terhadap implementasi suatu kebijakan, maka hal ini akan menyebabkan ketidak efektifan dan menghambat jalanya pelaksanaan kebijakan.

Hasil penelitian menunjukkan bahwa dimensi struktur birokrasi berpengaruh terhadap efektivitas implementasi BOS di Kecamatan Tambak. dilihat dari koefisien kendall's tau b yang dihasilkan yakni $0,525^{* *}$ hal ini menunjukkan ada pengaruh yang sedang dengan arah yang positif artinya semakin tinggi stuktur birokrasi (X4) semakin tinggi pula efektifitas implementasi BOS di Kecamatan Tambak (Y) dan sebaliknya semakin rendah struktur birokrasi semakin rendah pula efektivitas implementasi BOS di kecamatan Tambak seperti yang dihasilkan dari uji regresi ordinal dengan estimate semakin buruk struktur birokrasi di lokasi penelitian maka akan semakin menurunkan efektivitas implementasi BOS. 
Dari hasil observasi dan dokumentasi, struktur birokrasi di Kecamatan Tambak dalam implementasi BOS berjalan dengan cukup baik namun belum sepenuhnya optimal. Dalam struktur organisasi sekolah, tersedia pembagian kerja pada masing-masing staff. Selain itu sekolah juga mempunyai job description untuk masing-masing jabatan dimana masing-masing pelaksana bertanggung jawab atas pekerjaanya masing-masing. Adanya system monitoring dan pengawasan terhadap BOS, maka para pelaksana tidak dapat menyalah gunakan tanggung jawab yang diberikan terkait pengelolaan BOS. Untuk menghindari kesalahan para pelaksana berpedoman pada juknis dan juklis BOS yang terbaru sebagai acuan. Pelaksanaan monitoring BOS dilakukan oleh berbagai pihak antara lain kepala sekolah, pengawas sekolah dan pengawas BOS dari dinas Kabupaten serta rektorat dan KPK Kabupaten. Edward III (dalam Subarsono, 2011 : 90) berpendapat bahwa sumber-sumber penting dalam mendukung pelaksanaan implementasi kebijakan pemerintah antara lain struktur birokrasi yang terdiri dari adanya SOP dan pembagian kerja.

Sejalan dengan hasil penelitian dari Ninik Purwaning S (2010), Desy Natalia Krisdayanti (2014), Abdullah Wahid (2014), dan Yuyun Sefri Setyaningrum (2016) yang menjelaskan bahwa struktur birokrasi turut memberikan andil terhadap implementasi kebijakan.

Kendala dalam aspek struktur birokrasi yakni terkait prosedur operasi standar (standars Operating procedures atau SOP). SOP menjadi pedoman bagi setiap implementor dalam bertindak. Struktur organisasi yang terlalu panjang dalam implementasi BOS, melemahkan pengawasan dan menimbulkan red-tape, yakni prosedur birokrasi yang rumit dan kompleks yang pada gilirannya menyebabkan aktivitas organisasi tidak fleksibel. SOP dapat menghalangi pelaksanaan kebijakan-kebijakan baru yang memerlukan cara dan personal baru. Meskipun begitu, organisasi-organisasi yang memiliki prosedur perencanaan yang fleksibel dan memiliki kewenangan yang cukup dalam melaksanakan program akan lebih gampang menyesuaikan dirinya terhadap tanggung jawabnya. Hal tersebut menjadi bukti nyata, bahwa adanya pembagian kerja, formalisasi, garis komando serta SOP dapat mempengaruhi efektivitas implementasi BOS pada SDN di Kecamatan Tambak. 


\section{KESIMPULAN DAN IMPLIKASI}

\section{Kesimpulan}

Berdasarkan hasil penelitian menunjukkan bahwa komunikasi berpengaruh terhadap efektifitas implementasi program BOS di kecamatan Tambak sebesar $84,9 \%$, sumber daya berpengaruh sebesar $81,8 \%$, disposisi berpengaruh sebesar $82,1 \%$, struktur birokrasi berpengaruh sebesar 52,5\% dan seluruhnya memiliki arah positif dan juga signifikan.Secara bersamasama komunikasi, sumber daya, disposisi dan struktur birokrasi berpengaruh terhadap efektivitas implementasi program bantuan operasional sekolah di kecamatan tambak sebesar 86,4 \% menunjukkan adanya pengaruh yang sangat kuat dan signifikan dengan arah yang positif berarti semakin tinggi intensitas komunikasi, sumber daya, disposisi dan struktur birokrasi maka semakin tinggi pula efektivitas implementasi BOS di Kecamatan Tambak, begitu juga sebaliknya.

\section{Implikasi}

Berdasarkan kesimpulan di atas, impilkasi dalam upaya meningkatkan dukungan efektivitas implementasi BOS, sebagai berikut :

a. Implementasi BOS di kecamatan tambak tetap dipertahankan intensitas komunikasi yang efektif, baik dalam sosialisasi BOS maupun pertemuan berkala.

b. Dalam Implementasi BOS di kecamatan tambak perlu digali sumber daya di sekolah seperti guru dan tenaga kependidikan lain secara efektif baik dalam pengelolaan maupun pertanggung jawaban atas pelaporan BOS.

c. Implementasi BOS di kecamatan tambak perlu mendapat dukungan penuh dan kerja sama dengan komite dan wali murid agar tetap mendukung kelancaran dan efektifitas program BOS.

d. Dalam Implementasi BOS di kecamatan tambak hendaknya pembagian staff dan fragmentasi dapat diatur lebih efektif dan fleksibel agar tujuan pengelolaan dana BOS dapat tercapai. 


\section{DAFTAR PUSTAKA}

Azwar, Saifudin. 2009. Sikap Manusia Teori Dan Pengukuran. Yogyakarta : Pustaka Pelajar

Depdiknas. Buku Panduan Bos Dalam Rangka Wajib Belajar 9 Tahun. Jakarta

Edwards, George C, III. 1980. Implementing Public Policy. Washington Dc : Texas A \& M University . Congretional Quarterly Press

Grindle, Merilee S. 1980. Politics And Apolicy Implementation In The Third Word. New Jersey : Princetown University

Gunawan, Ade. 2003. Analisis Customer Decision Model Untuk Pengukuran Efektifitas. Jurnal Ilmiah Manajemen Dan Bisnis, Vol 3 No 1

Isna, A Dan Warto. 2013. Analisis Data Kuantitatif : Panduan Praktis UntukPenelititan Sosial : Dilengkapi Dengan Analisis Regresi Nominal Dan Ordinal. Purwokerto : Stain Press

Sagala, Syaiful. 2008. Budaya Dan Reinventing Budaya Organisasi Pendidikan. Bandung; Alfabeta

Siagian, Sondang P. 2003. Fungsi-Fungsi Manajerial, Edisi Revisi. Jakarta : Bumi Aksara

Steers, RM. 1995. Efektivitas Organisasi : Kajian Perilaku. Terjemahan. Jakarta : Erlangga

Sugiyono. 2012. Metode Penelitian Manajemen Pendekatan : Kuantitatif, Kualitatif, Kombinasi (Mixed Methods),Penelitian Tindakan (Action Research) Dan Penelitian Evaluasi. Bandung : Alfabeta

Wahab, Solichin Abdul. 2007. Analisis Kebijaksanaan : Dari Formulasi Ke Implementasi Kebijaksanaan Negara. Jakarta : Sinar Grafika

Widodo. 2010. Implementasi kebijakan. Yogyakarta : Andi Offset

Abdullah, Wahid. 2014. Implementasi Kebijakan Bantuan Dana Biaya Operasional Sekolah (BOS) Di Kota Palu. Universitas Tabulako 
Desy Natalia Krisdayanti. 2014. Implementasi Program Bantuan Operasional Sekolah (Bos) Oleh Pemerintah Daerah Dan Sekolah Menengah Pertama. Universitas Udayana 